\title{
OREX-1019: A Novel Treatment of Opioid Use Disorder and Relapse Prevention ${ }^{\llbracket}$
}

\author{
(1) David R. Maguire, Lisa R. Gerak, Gerta Cami-Kobeci, (1)Stephen M. Husbands, \\ Charles P. France, Barbara Belli, and Peter Flynn \\ Departments of Pharmacology (D.R.M., L.R.G., C.P.F.) and Psychiatry (C.P.F.), and Addiction Research, Treatment \& Training \\ Center of Excellence (D.R.M., L.R.G., C.P.F.), University of Texas Health Science Center at San Antonio, San Antonio, Texas; \\ Department of Pharmacy and Pharmacology (G.C.-K., S.M.H.) and Centre for Therapeutic Innovation (S.M.H.), University of Bath, \\ Bath, United Kingdom; and Orexigen Therapeutics, La Jolla, California (B.B., P.F.)
}

Received July 16, 2019; accepted November 13, 2019

\begin{abstract}
There is an urgent need for new pharmacological treatments for substance use disorders, including opioid use disorder, particularly for use in relapse prevention. A combination of buprenorphine with naltrexone has shown particular promise, with clinical studies indicating a substantial improvement over treatment with naltrexone alone. OREX-1019 (formerly BU10119) is a compound that mimics the pharmacology of the buprenorphine/naltrexone combination. This study evaluated, in rhesus monkeys, the therapeutic potential of OREX-1019 for treating opioid use disorder. Pretreatment with OREX-1019 (0.01-0.3 mg/kg s.c.) dose-dependently decreased responding for the $\mu$ opioid receptor agonist remifentanil in rhesus monkeys but did not maintain levels of responding above vehicle when it was available for self-administration. OREX-1019 (0.01-1.0 mg/kg s.c.) also decreased cue- plus heroin-primed reinstatement of extinguished responding in monkeys that self-administered remifentanil but did not alter cue- plus cocaine-primed reinstatement of responding in monkeys that self-administered cocaine. OREX1019 (0.3 mg/kg s.c.), like naltrexone (0.1 mg/kg s.c.), increased
\end{abstract}

heart rate and blood pressure, produced overt observable signs, and eliminated food-maintained responding in monkeys treated chronically with morphine. These results confirm that OREX1019 has little or no efficacy at $\mu$ opioid receptorsand has low abuse potential, and, combined with promising safety (clean profile vs. other off-target proteins including the hERG (human ether-a-go-go-related gene) $\mathrm{K}^{+}$channel) and pharmacokinetic data (supporting administration by subcutaneous or sublingual routes, but with low oral bioavailability), suggest it could be a safe and effective alternative to current treatments for opioid use disorders particularly as applied to relapse prevention.

\section{SIGNIFICANCE STATEMENT}

The novel opioid OREX-1019 potentially provides an improved relapse prevention agent for use in opioid use disorder. The current study demonstrates that in monkeys OREX-1019 is able to inhibit the self-administration of, and cue- plus heroinprimed reinstatement of, responding previously maintained by remifentanil.

\section{Introduction}

Buprenorphine is a successful treatment of opioid abuse and dependence, with evidence from clinical and/or animal studies that it may also reduce cocaine and alcohol use (McCann, 2008). Its receptor profile is that of a high-affinity $\mu$ opioid receptor (MOPr) partial agonist, a high-affinity $\kappa$ opioid receptor (KOPr) antagonist, a high-affinity $\delta$ opioid receptor (DOPr) antagonist, and a low-affinity nociceptin receptor (NOPr) partial agonist (Husbands, 2013). The MOPr

The majority of this work was supported by Orexigen Therapeutics and, in part, supported by the National Institutes of Health National Institute on Drug Abuse [Grant R01DA07315 (S.M.H.)].

B.B. and P.F. were employed by Orexigen Therapeutics while engaged in this research project. S.M.H. is an inventor on the patent that describes OREX1019/BU10119 and was a consultant to Orexigen Therapeutics during this project.

https://doi.org/10.1124/jpet.119.261511.

S This article has supplemental material available at jpet.aspetjournals.org. partial agonist effects of buprenorphine, although crucial for its current use in treating opioid use disorder (OUD), preclude its use in preventing opioid relapse and in the treatment of cocaine or alcohol abuse in cases where there is no concurrent opioid abuse because use of buprenorphine is associated with a significant level of opioid physical and psychologic dependence (Johanson et al., 2012).

Antagonism of KOPr by buprenorphine also likely plays a role in its clinical use for OUD. There is now substantial evidence that KOPr antagonists inhibit stress-induced, but not drug primeinduced, reinstatement of drug-seeking behavior (Bailey and Husbands, 2014) and attenuate a diverse range of stress-induced behaviors, suggesting a role for KOPr antagonists as stressresilience medications (Chavkin, 2018). KOPr antagonists also have anxiolytic-like and antidepressant-like effects in various behavioral paradigms (for a review, see Van't Veer and Carlezon, 2013).

An optimal pharmacological treatment of relapse in recovering opioid or cocaine abusers might be a drug that retains

ABBREVIATIONS: AUC, area under the time-concentration curve; DOPr, $\delta$ opioid receptor; FR, fixed ratio; GI, gastrointestinal; KOPr, $\kappa$ opioid receptor; MOPr, $\mu$ opioid receptor; NOPr, nociceptin receptor; OUD, opioid use disorder; PK, pharmacokinetic; p.o., oral; s.I., sublingual; $T_{\text {max }}$, time to reach maximum plasma concentration. 
the KOPr and DOPr antagonist and NOPr partial agonist properties of buprenorphine but with less efficacy at MOPr. Given the effectiveness of naltrexone (Rösner et al., 2010) and nalmefene (Forray and Sofuoglu, 2014), which are MOPr antagonists, this novel medication would also be expected to have utility in the treatment of alcohol abuse. Interestingly, the effectiveness of naltrexone for preventing relapse to alcohol use is also observed in individuals with dual cocaine/ alcohol use disorders (Hersh et al., 1998), supporting a role for MOPr antagonism in reducing alcohol intake in polydrug abusers.

Further support for a target profile of $\mathrm{MOPr}, \mathrm{KOPr}$, and DOPr antagonism plus NOPr partial agonism is available from studies of combinations of buprenorphine with MOPr antagonists, with the latter in sufficient quantities to ensure very little residual agonist activity at MOPr. For example, a combination of buprenorphine and naltrexone completely blocked drug-primed reinstatement of conditioned-place preference in cocaine-trained rats and significantly attenuated drug-primed reinstatement in morphine-trained rats (Taverner et al., 2011; Cordery et al., 2014). Because selective KOPr antagonists alone do not block drug-primed reinstatement, these results suggest the actions of the mixture are greater than those of a KOPr antagonist alone. Encouraging results have also been observed in two clinical trials using a combination of buprenorphine and naltrexone (Rothman et al., 2000; Gerra et al., 2006). The combination proved effective in reducing relapse in individuals recovering from OUDand significantly reduced cocaine use.

Work by Falcon et al. (2016) and Robinson et al. (2017) demonstrated a role for both MOPr antagonist and KOPr antagonist activities in the antidepressant-like effects of buprenorphine, further supporting the benefits of a multiple receptor approach for developing more effective medications. Another product, ALKS 5461 developed by Alkermes, combines buprenorphine with the MOPr antagonist samidorphan, and, although the combination has not received regulatory approval, reports suggest a mixture of $2 \mathrm{mg}$ buprenorphine and $2 \mathrm{mg}$ samidorphan might be effective in treating major depressive disorder (Peckham et al., 2018). Taken together, studies to date indicate there are significant translational opportunities for any single compound that can mimic a mixture of buprenorphine and a MOPr antagonist.

To this end, the synthesis and initial in vitro pharmacology of OREX-1019 were described previously (Cueva et al., 2015). It is an antagonist or low-efficacy partial agonist at MOPr, an antagonist at KOPr and DOPr, and a partial agonist at NOPr with slightly higher efficacy at NOPr compared with buprenorphine. OREX-1019 can therefore be considered as equivalent to buprenorphine but with substantially reduced efficacy at MOPr. Studies in mice, which demonstrated that OREX1019 has antidepressant-like effects, also showed that it was an antagonist at KOPr and MOPr, as evidenced by attenuation of the antinociceptive effects of morphine, buprenorphine, and U50,488 (Almatroudi et al., 2018). Importantly, OREX1019 did not have significant locomotor or rewarding effects at doses that have antagonist effects. Because OREX-1019 has these pharmacological properties, it might also have effects that predict effectiveness in treating ongoing drug abuse and/ or preventing relapse. The current study investigated effects of OREX-1019 in rhesus monkeys to evaluate its potential effectiveness as a novel treatment of OUD. In addition, although OREX-1019 was previously evaluated in mice for its therapeutic potential as an antidepressant (Almatroudi et al., 2018), the in vivo pharmacokinetic (PK) properties largely remain unknown. Therefore, its PK parameters were evaluated further in rats, rabbits, and nonhuman primates.

\section{Materials and Methods}

Animals. Experiments related to potential treatment of OUD were evaluated in 15 adult rhesus monkeys [nine males (AC, AP, CH, DU, FI, GU, MA, MU, NA) and six females (DAH, DAI, GA, PR, RU, SO)], weighing between 5.9 and $12.1 \mathrm{~kg}$ that were housed individually in stainless steel cages in colony rooms maintained under a 14/10-hour light/dark cycle (lights on at 0600 hours). Monkeys were fed chow (High Protein Monkey Diet; Harlan Teklad, Madison, WI), fresh fruit, peanuts, and other treats daily, and water was continuously available. Studies were carried out in accordance with the Guide for the Care and Use of Laboratory Animals, as adopted and promulgated by the United States National Institutes of Health (National Research Council 2011), and were approved by the University of Texas Health Science Center at San Antonio Institutional Animal Care and Use Committee.

Male Sprague-Dawley rats (Charles River, Calco, Italy) were used in studies measuring gastrointestinal (GI) transit and Rotorod performance. Rats were housed in solid-bottom cages with sawdust litter. They were maintained on a 12-hour light/dark cycle. Food (rat maintenance diet Altromin $\mathrm{R}$ supplied by A. Rieper SpA, Bolzano, Italy) and water were available ad libitum. Animals were housed, and experiments were performed, in accordance with the Association for Assessment and Accreditation of Laboratory Animal Care.

Surgery. Monkeys were sedated with $10 \mathrm{mg} / \mathrm{kg}$ (i.m.) ketamine (Henry Schein Animal Health, Dublin, OH), intubated, and then maintained on $2 \mathrm{l} / \mathrm{min}$ oxygen and isoflurane anesthesia (Butler Animal Health Supply, Grand Prairie, TX). For monkeys participating in self-administration and reinstatement experiments, a 5-French polyurethane catheter (Access Technologies, Skokie, IL) was inserted into a vein (e.g., jugular or femoral), tunneled subcutaneously (s.c.) to the midscapular region of the back, and attached to a s.c. vascular access port (MIDA-PU-C50; Access Technologies). Monkeys in the antagonist-precipitated withdrawal study were sedated, as described above, and a telemetry transmitter (PhysioTel Digital Implant model L11; Data Science International, Arden Hills, MN) was placed in the left or right flank, with positive ECG leads tunneled to the lower-left quadrant of the thorax, negative ECG leads tunneled to the upperright quadrant, and the systemic blood pressure catheter tunneled to and inserted into the left or right femoral artery. Penicillin B\&G $(40,000 \mathrm{IU} / \mathrm{kg})$ and meloxicam $(0.1-0.2 \mathrm{mg} / \mathrm{kg})$ were given postoperatively.

OREX-1019 Self-Administration. During drug self-administration sessions, monkeys were seated in primate chairs (Model R001; Primate Products, Miami, FL) and positioned in sound-attenuating operantconditioning chambers containing two horizontally aligned response levers located approximately $32 \mathrm{~cm}$ apart. Above each lever was a circular, translucent disk that could be transilluminated green or red. Selfadministered drug infusions were delivered intravenously (i.v.) by connecting a 185-cm extension set (Abbott Laboratories, Stone Mountain, GA) to the vascular access port by a 20-g Huber-point needle (Access Technologies). The distal end of the extension set was connected to a 30- or 60-ml syringe mounted in a syringe driver (PHM-100; Med Associates, St. Albans, VT) located outside the chamber. Extraneous sounds were masked by white noise and an exhaust fan. Experimental events were arranged, and data were recorded by an interface (Med Associates) connected to a PC computer operating Med-PC IV software (Med Associates).

Prior to the start of the session, the port and catheter were flushed with $5 \mathrm{ml}$ sterile $0.9 \%$ saline solution, and a syringe and extension set containing the solution available for self-administration that day was connected to the Huber and mounted in the syringe pump. One minute 
before the start of the session, the pump was activated to load the catheter with the new solution. Sessions began with noncontingent delivery of a priming infusion; a light over the active lever was illuminated red for 5 seconds, and the dose of drug available for selfadministration during that session was delivered. Immediately after the priming infusion, one of the side lights (counterbalanced across monkeys) was illuminated green, signaling the beginning of the response period. Thirty consecutive responses [fixed-ratio (FR) 30 schedule] on the lever directly below the green light (active lever) changed the light from green to red for 5 seconds and delivered an i.v. infusion. Completion of the response requirement also initiated a 180second timeout, during which all lights were off and responses were recorded, but had no programmed consequence. Following the timeout, the same side light was illuminated green once again, signaling the next response period. Responses on the other (inactive) lever during response periods reset the response counter for the active lever and had no other scheduled consequence. Lever designations remained constant for each monkey for the duration of the study. Sessions lasted for 90 minutes, inclusive of response and timeout periods. At the end of the session, the catheter and port were flushed and locked with $3 \mathrm{ml}$ heparinized saline $(100 \mathrm{U} / \mathrm{ml})$ to maintain catheter patency.

Reinforcing effects of OREX-1019 were evaluated in four monkeys (AC, FI, PR, RU). Initially, responding was maintained by delivery of $0.00032 \mathrm{mg} / \mathrm{kg}$ per infusion of the MOPr agonist remifentanil for at least five sessions. Responding for remifentanil was considered stable when monkeys obtained at least 20 infusions during the last three consecutive sessions, and the average number of infusions obtained in each of those three sessions varied by not more than $\pm 20 \%$ of the three-session mean. Thereafter, vehicle was substituted for remifentanil for a minimum of four sessions and until eight or fewer infusions were obtained for the last three consecutive sessions. After the initial tests with remifentanil and vehicle, effects of increasing unit doses of OREX-1019 $(0.01,0.03,0.1,0.3$, and $1.0 \mathrm{mg} / \mathrm{kg}$ per infusion) were determined; each test lasted for a minimum of five sessions and until responding met the criteria for stability with either remifentanil or vehicle, as described above, or for up to 10 sessions, whichever occurred first. Unit doses of OREX-1019 were tested in ascending order in all monkeys, and all tests were separated by an intervening vehicle substitution test. Effects of remifentanil were redetermined two more times during the experiment, once between tests with 0.1 and $0.3 \mathrm{mg} / \mathrm{kg}$ per infusion of OREX-1019 and again at the end of the experiment, following the test with $1.0 \mathrm{mg} / \mathrm{kg}$ per infusion of OREX1019. Initially, remifentanil and OREX-1019 $(0.01-0.1 \mathrm{mg} / \mathrm{kg}$ per infusion) were dissolved in a $10 \% \mathrm{w} / \mathrm{v} \beta$-cyclodextrin vehicle. Because OREX-1019 had limited solubility, tests with the two largest unit doses of OREX-1019 (0.3 and $1.0 \mathrm{mg} / \mathrm{kg}$ per infusion $)$ as well as the second and third tests with remifentanil were conducted using a $45 \% \mathrm{w} / \mathrm{v} \beta$-cyclodextrin vehicle. In addition, the infusion duration was lengthened by 2.5 -fold to achieve the largest unit dose of OREX$1019(1.0 \mathrm{mg} / \mathrm{kg}$ per infusion); the final tests with vehicle and remifentanil were also conducted using the longer infusion duration (i.e., a 2.5-fold lower concentration of remifentanil was in the syringe). For the entire experiment, infusion durations ranged from 14 to 46 seconds, with each infusion delivering 1 to $2.5 \mathrm{ml}$ of solution per $10 \mathrm{~kg}$ body weight.

For the OREX-1019 self-administration experiment, infusions obtained during the last three sessions of each phase were averaged for individual monkeys. Dose-effect data were analyzed using a onefactor, repeated-measures ANOVA on the number of infusions obtained for the first and last remifentanil and vehicle conditions as well as each unit dose OREX-1019, followed by Dunnett's post hoc multiple comparisons test comparing all conditions to the first vehicle test.

OREX-1019 Suppression of Remifentanil Self-Administration. Effects of OREX-1019 pretreatment on remifentanil self-administration were evaluated in four monkeys (AC, GU, NA, PR). Responding delivered $0.00032 \mathrm{mg} / \mathrm{kg}$ per infusion of remifentanil dissolved in saline; other procedural details were as described above. In addition, monkeys received a s.c. injection 15 minutes prior to each session. During baseline, monkeys received an injection of $0.4 \mathrm{ml}$ of $45 \% \mathrm{w} / \mathrm{v} \beta$-cyclodextrin vehicle. Once responding was stable, an injection of OREX-1019 $(0.01-0.3 \mathrm{mg} / \mathrm{kg})$ was given prior to one session, with each test injection followed by three baseline sessions before which monkeys received vehicle. Stability was defined by three consecutive sessions in which at least 20 infusions of remifentanil were obtained and the average number of infusions obtained in each of those three sessions varied by not more than $\pm 20 \%$ of the threesession mean. Doses of OREX-1019 were tested in ascending order, up to a dose that decreased the number of remifentanil infusions obtained to $<25 \%$ of baseline $(0.1 \mathrm{mg} / \mathrm{kg}$ for monkey AC) or up to $0.3 \mathrm{mg} / \mathrm{kg}$ (monkeys GU, NA, and PR).

For effects of OREX-1019 pretreatment on remifentanil selfadministration, the number of infusions of remifentanil obtained during the three sessions immediately preceding the first test with OREX-1019 was averaged for individual monkeys to determine the baseline level of responding for remifentanil (i.e., following vehicle administration). OREX-1019 dose-effect data were analyzed using a one-factor, repeated-measures ANOVA on the number of infusions obtained during baseline and following treatment with each dose of OREX-1019, followed by Dunnett's post hoc multiple comparison tests.

OREX-1019 Suppression of Responding Reinstated by Drug-Paired Stimuli Plus Noncontingent Infusion of Drug. Effects of OREX-1019 on reinstatement of responding previously maintained by remifentanil or cocaine were studied in seven monkeys (CH, DAH, DAI, GA, GU, MU, NA). Initially, responding resulted in delivery of $0.00032 \mathrm{mg} / \mathrm{kg}$ per infusion of remifentanil (DAH, GA, GU, $\mathrm{NA}$ ) or $0.032 \mathrm{mg} / \mathrm{kg}$ per infusion of cocaine (CH, DAI, GA, MU) under the self-administration procedure described above, and monkeys received a s.c. injection 15 minutes prior to each session. Once responding during baseline self-administration sessions was stable, as defined by $\leq 20 \%$ difference in number of responses with no increasing or decreasing trend across the last three self-administration sessions, extinction sessions were introduced during which stimuli associated with drug during self-administration sessions (i.e., the green discriminative stimulus and the red stimulus previously paired with delivery of a drug infusion) were not presented and infusions were not delivered, although responses were recorded. Stimuli were omitted from extinction sessions, so that effects of the presentation of cues alone on reinstated responding could be measured. Extinction sessions were conducted until the total number of responses in a session decreased to $<10 \%$ of drug-reinforced responses for one session. Thereafter, a reinstatement session was conducted. Immediately before the reinstatement session, saline or drug (heroin or cocaine) was injected into the vascular access port before it was connected to a syringe containing saline located in the syringe pump. When the syringe pump was activated at the beginning of the session to fill the catheter with saline, the solution in the port (i.e., saline or drug) was delivered. For monkeys who responded for remifentanil during self-administration sessions, $0.032 \mathrm{mg} / \mathrm{kg}$ heroin was given noncontingently at the beginning of reinstatement sessions. Heroin was used to reinstate responding rather than remifentanil because of its longer duration of action, and this dose of heroin was chosen because it is the smallest dose of heroin that significantly increased reinstated responding, compared with responding during extinction (Gerak et al., 2019). For monkeys who responded for cocaine during self-administration sessions, $0.32 \mathrm{mg} / \mathrm{kg}$ cocaine was given noncontingently at the beginning of reinstatement sessions, and this dose of cocaine was chosen because it is the smallest dose of cocaine that increased responding above that produced by presentation of drugassociated stimuli alone (Gerak et al., 2016). The green light above the active lever was then illuminated, and 30 responses on that lever turned the green light off, illuminated the red light for 5 seconds, and initiated a 180-second timeout, although no infusion was delivered. Only one reinstatement session was presented for each test, followed immediately by a baseline self-administration session.

For each subject, at least two reinstatement tests were conducted in which vehicle alone ( $45 \% \mathrm{w} / \mathrm{v} \beta$-cyclodextrin) was given s.c. 15 minutes 
before sessions and noncontingent drug (heroin or cocaine) was given i.v. at the beginning of the session. Effects of OREX-1019 pretreatment on reinstated responding were determined by giving a single dose of OREX-1019 $(0.01-0.1 \mathrm{mg} / \mathrm{kg}) 15$ minutes before a reinstatement session in which either heroin or cocaine was given noncontingently and drug-associated stimuli were presented. The session immediately following a reinstatement session was a baseline self-administration session.

The number of responses that occurred on the active lever in the presence of the green stimulus light during reinstatement sessions (i.e., responses that were reinforced by presentation of drug-associated stimuli) was plotted as a function of dose of OREX-1019. Effects of OREX-1019 on heroin- and cocaine-reinstated responding were analyzed separately using a one-factor, repeated-measures ANOVA, followed by post hoc Dunnett's post hoc multiple comparison tests.

Withdrawal Precipitated by OREX-1019 and Naltrexone. Monkeys (AP, DU, MA, SO) were instrumented with telemetry devices and participated in operant conditioning sessions conducted in their home cage. A stainless steel instrument panel $(20 \mathrm{~cm}$ high by $28 \mathrm{~cm}$ wide) was mounted on one wall of the cage that contained two 4.5$\mathrm{cm}$-wide response levers, positioned $23 \mathrm{~cm}$ above the cage floor and spaced $15 \mathrm{~cm}$ apart center to center; two metal partitions attached to the instrument panel between the levers prevented responding on both levers simultaneously with the same limb. Three stimulus lights were horizontally aligned $5 \mathrm{~cm}$ above the levers. Directly above the instrument panel was a 6 -cm-high by 5 -cm-wide aperture through which 300-mg raspberry-flavored sucrose pellets (5TUT; Test Diet, Richmond, IN) were delivered via activation of a pellet dispenser (Med Associates, Fairfax, VT).

Food-Maintained Operant Behavior. Daily sessions comprised five response periods beginning at 1000, 1030,1100, 1130, and 1200 hours. The beginning of a response period was signaled by illumination of the green light above the right lever; 10 responses on the right lever (FR 10) delivered one food pellet and turned off the green light for 0.5 seconds. Response periods ended after 10 food presentations or 10 minutes, whichever occurred first. All stimulus lights were turned off between response periods, and responding during that time had no scheduled consequence. Monkeys were given their daily ration of chow, fresh fruit, and peanuts approximately 2 hours after the session ended ( 1430 hours).

Telemetry. Mean arterial pressure (millimeters of mercury), heart rate (beats per minute), body temperature (degree Celsius), and activity (cpm) were collected every minute. Some of these physiologic parameters are altered during withdrawal from $\mathrm{MOPr}$ agonists in nonhuman primates (blood pressure was not measured previously; Becker et al., 2008; Gerak et al., 2009, 2015; Gerak and France, 2016).

Behavioral Observations. Two individuals monitored directly observable signs. The observers were blinded with regard to the test injections. During an observation period, the presence or absence of 15 signs (body tremor, twitch, wet-dog shake, lying down, scratching, grimace, unusual tongue movement, protrusion of tongue, salivation, vocalization, yawning, eye-closing, emesis, holding abdomen, and head shaking; Becker et al., 2008) was noted during 15-second intervals; these signs have been monitored previously during withdrawal from MOPr agonists in nonhuman primates (Becker et al., 2008; Gerak et al., 2009, 2015; Gerak and France, 2016). Each observation period lasted for eight intervals and a total of 2 minutes of observation time per monkey.

Chronic Morphine Treatment. Once food-maintained responding was stable, as defined by three consecutive sessions in which the average response rate across the five intervals in each of those three sessions varied by not more than $\pm 20 \%$ of the three-session mean, monkeys began receiving twice-daily injections, one at 0700 hours and another at 1700 hours. Initially, both injections were saline. Then morphine was substituted for both injections starting with $1.0 \mathrm{mg} / \mathrm{kg}$ and increasing in quarter-log units over the course of 6 to 8 weeks to a maximum of $3.2 \mathrm{mg} / \mathrm{kg}$, while maintaining stable food-maintained responding. Once the dose given in the afternoon reached $3.2 \mathrm{mg} / \mathrm{kg}$ and food-maintained responding was stable, the morning dose of morphine was titrated to the largest dose, on a quarter-log unit scale, that could be given without significantly disrupting responding for food during operant conditioning sessions that began 3 hours after the morning injection ( 1000 hours). The final dose of morphine given in the morning was $1.78 \mathrm{mg} / \mathrm{kg}$ for AP, DU, and MA and $0.32 \mathrm{mg} / \mathrm{kg}$ for SO. Prior to the first test, monkeys were treated twice daily with morphine for a total of 72 days and treated with the final daily doses for at least 18 days.

During each test, monkeys received an additional daily injection at 0945 hours, 15 minutes prior to the start of the operant conditioning session. Tests were conducted in 3-day units, comprising an injection of $0.4 \mathrm{ml}$ vehicle $(45 \% \mathrm{w} / \mathrm{v} \beta$-cyclodextrin) on day 1 , an injection of either naltrexone $(0.1 \mathrm{mg} / \mathrm{kg})$ or OREX-1019 $(0.3 \mathrm{mg} / \mathrm{kg})$ on day 2 , and no injection on day 3 . The dose of naltrexone was chosen because it is at least 10 -fold larger than a dose that reliably precipitates withdrawal in rhesus monkeys treated chronically with a MOPr agonist (e.g., Becker et al., 2008); the dose of OREX-1019 was chosen because it reliably decreased remifentanil self-administration in rhesus monkeys (see below).

For the first two test days, behavioral observations occurred at $0930,1015,1045,1115$, and 1245 hours, corresponding to 15 minutes before and 30, 60, 90, and 180 minutes after the test injection. Collection of telemetry data began at 1700 hours the day prior to the first day of the test and continued through 1600 hours on the third day. Naltrexone was studied first in all monkeys, followed 1 week later by OREX-1019. During tests, monkeys continued to receive both daily injections of morphine at the normally scheduled times; test injections (i.e., vehicle, naltrexone, and OREX-1019) were administered 2 hours and 45 minutes following the morning morphine injection.

For monkeys receiving morphine daily, response rate was calculated for each response period by dividing the number of responses by the total time that the green light was illuminated. Telemetry data were collected each minute and then averaged across 1-hour bins, beginning 1 hour prior to the daily test injection and continuing for up to 4 hours after the test injection; the first bin started at 0845 hours. For behavioral observations, each sign was noted as present or absent during each of the eight 15-second intervals, and a total was calculated by summing across intervals and signs for each observation period. Data for all three measures were analyzed using two-way, repeatedmeasures ANOVA with day of treatment and time of day as factors.

GI Transit. Because other MOPr agonists are known to decrease gut motility, the effects of OREX-1019 on GI transit were evaluated in male Sprague-Dawley rats (8 to 9 weeks old). One group was treated with vehicle only (control), and other groups were administered 3, 30, or $100 \mathrm{mg} / \mathrm{kg}$ OREX-1019 or $30 \mathrm{mg} / \mathrm{kg}$ morphine $(N=10$ for each group). Within each group, dosing of each rat was performed in approximately 5 -minute intervals. Food, but not water, was withheld the night before experimentation. Rats were removed from the cage, administered OREX-1019, morphine, or vehicle by s.c. injection, and then returned to the home cage. Two milliliters of charcoal suspension (formulated by suspending charcoal and plain flour in water for injection in the ratio 1:3:6) was administered by gavage to the rats 120 minutes after the injection. Thirty minutes after being given the charcoal meal, rats were anesthetized with isoflurane and sacrificed via cervical dislocation, at which point the intestine was exposed. The distance that the charcoal meal traveled along the intestine from the pyloric sphincter as well as total intestinal length was measured. Data were expressed as a ratio by dividing the distance that the charcoal meal traveled by total intestine length. Between-groups differences in the GI transit ratio were analyzed using a one-way ANOVA, followed by Dunnett's post hoc multiple comparisons test. $P<0.05$ was considered statistically significant.

Rotorod. Sedative effects of OREX-1019 were determined using the Rotorod test in male Sprague-Dawley rats weighing between 250 and $300 \mathrm{~g}$. On day 1, rats were placed on the Rotarod apparatus (model 47700; Ugo Basile, Italy) and allowed to walk at a fixed speed (4 rpm) 
for at least 120 seconds before being returned to the home cage. After 4 hours, rats were placed on the apparatus again, first at a fixed speed (4 rpm) for 60 seconds and then at accelerating speeds (4-40 rpm) for at least $100-120$ seconds. On day 2 , rats were placed on the Rotarod first at a fixed speed ( $4 \mathrm{rpm})$ for 60 seconds and then at accelerating speeds (4-40 rpm) until the rat fell off or for up to 300 seconds, whichever occurred first; the latency to fall was recorded and used as the pretreatment (baseline) measurement. On day 3 (test day), rats were treated with drug or vehicle and then placed on the Rotarod first at fixed speed ( $4 \mathrm{rpm})$ for 60 seconds and then at accelerating speeds (4-40 rpm); the latency to fall was recorded and used as the post-treatment measurement. One group was treated with vehicle only, and other groups were administered 10,30 , or $100 \mathrm{mg} / \mathrm{kg}$ OREX-1019 or $10 \mathrm{mg} / \mathrm{kg}$ diazepam ( $N=10$ for each group). OREX-1019 was administered s.c. 120 minutes before the test; diazepam was administered i.p. 30 minutes before the test. Pretreatment latency was subtracted from the post-treatment latency to determine a change score; negative change scores indicate that the treatment decreased time on the Rotorod, indicative of a sedative effect. Between-groups differences in change scores were analyzed using a oneway ANOVA, followed by Dunnett's post hoc multiple comparisons test. $P<0.05$ was considered statistically significant.

ADMET and Selectivity. Screening in 62 radioligand/enzyme assays at two concentrations of OREX-1019 (100 and 10,000 nM) in duplicate wells was provided by National Institute on Drug Abuse (ATDP, Division of Pharmacotherapies and Medical Consequences of Drug Abuse). Human ether-a-go-go-related gene) $\mathrm{K}^{+}$(hERG) channel inhibition was carried out by Cyprotex using their standard protocol over a $8 \mathrm{~nm}$ to $25 \mu \mathrm{M}$ concentration range. P-gp substrate assessment in Caco-2 monolayers; inhibition of cytochrome P450 in human liver microsomes; stability in human, rat, and monkey plasma; whole blood; liver microsomes; liver S9 fraction; binding to human, rat, and monkey plasma proteins; and determination of octanol/buffer partition coefficient were carried out by Absorption Systems (Exton, PA).

The absolute bioavailability of OREX-1019 was evaluated in male Sprague-Dawley rats ( $N=3$ for each route of administration), male and female cynomolgus monkeys (two males and two females for each route of administration), and male New Zealand White rabbits $(N=5$ for each route of administration). Dosing routes in rats were i.v., s.c., and oral (p.o.); in monkeys were i.v. and p.o.; and in rabbits were i.v., sublingual (s.l.), and s.c.. Blood samples were collected by venepuncture, or jugular vein cannulae (rats), up to 24 hours after drug administration. Plasma concentrations of OREX-1019 were determined by liquid chromatography with tandem mass spectrometry (LC-MS/MS). Studies were carried out by Absorption Systems (rats and rabbits) and Covance Laboratories (Madison, WI; monkeys).

Pharmacokinetic parameters were calculated from the time course of the plasma concentrations using Phoenix WinNonlin (v7.0) software and a noncompartmental model. The maximum plasma concentrations $\left(\mathrm{C}_{\max }\right)$ after i.v. dosing were estimated by extrapolation of the first two time points back to $t=0$. The $C_{\max }$ and the time to reach maximum plasma concentration $\left(\mathrm{T}_{\max }\right)$ after p.o. and s.c. dosing were observed from the data. The area under the time-concentration curve (AUC) was calculated using the linear trapezoidal rule with calculation to the last quantifiable data point, and with extrapolation to infinity if applicable. Plasma half-life was calculated from 0.693/slope of the terminal elimination phase. Mean residence time was calculated by dividing the area under the moment curve by the AUC. Clearance was calculated from dose/AUC. Steady-state volume of distribution was calculated from clearance $\times$ mean residence time. Bioavailability was determined by dividing the individual dose normalized p.o. or s.c.. AUC values by the average dose normalized to i.v. AUC value. Any samples below the limit of quantitation $(0.5 \mathrm{ng} / \mathrm{ml})$ were treated as zero for pharmacokinetic data analysis.

Drugs. Remifentanil hydrochloride, morphine sulfate, heroin hydrochloride, naltrexone hydrochloride, and cocaine hydrochloride were generously provided by the National Institute on Drug Abuse Drug Supply Program (Rockville, MD); doses were calculated using the salt form. OREX-1019 was synthesized in-house according to the methods reported in Cueva et al. (2015) or purchased (Syncom, Groningen, The Netherlands); doses were calculated using the base with a correction factor of 1.07 (salt weight/base weight), and solutions with OREX-1019 were prepared fresh every 3 to 4 days. 2 -Hydroxypropyl- $\beta$-cyclodextrin was purchased (Accela ChemBio, San Diego, CA) and dissolved in sterile saline at a concentration of 0.1 or $0.45 \mathrm{~g} / \mathrm{ml}$. All self-administered drug was delivered i.v. in a volume of $1-2.5 \mathrm{ml} / 10 \mathrm{~kg}$ body weight. Heroin- and cocaine-priming injections in the reinstatement experiment were delivered i.v. in a volume of 0.15 to $0.6 \mathrm{ml}$, which insured that all drug remained in the port/catheter until the pump was activated and delivered the drug prime. Naltrexone and OREX-1019 pretreatments as well as daily morphine treatments were delivered s.c. in the lower back in a volume of $0.5-1.0 \mathrm{ml} / 10 \mathrm{~kg}$ body weight. For GI transit and Rotorod studies, morphine and diazepam were from stock held by Aptuit (Verona, Italy).

\section{Results}

\section{OREX-1019 Self-Administration}

When remifentanil was available at the beginning and end of the experiment, monkeys obtained an average ( \pm 1 S.E.M.) of $26.7 \pm 0.9$ and $22.3 \pm 2.8$ infusions, respectively (Fig. 1A, data above "Rem"). When $\beta$-cyclodextrin vehicle was substituted for drug at the beginning and end of the experiment, the number of infusions obtained decreased to $2.2 \pm 0.6$ and $0.2 \pm 0.2$, respectively (Fig. 1A, data above "V"). OREX1019 did not increase the number of infusions obtained across the range of doses tested. According to a repeated-measures ANOVA, there was a significant effect of condition $(\mathrm{F}[8,35]=$ 113.6, $P<0.001$ ); however, only remifentanil was significantly different from vehicle according to the Dunnett's post hoc test (filled diamonds).

\section{OREX-1019 Suppression of Remifentanil Self-Administration}

When remifentanil was available following $\beta$-cyclodextrin vehicle pretreatment, monkeys obtained an average of $27.1 \pm$ 0.5 infusions per session (Fig. 1B, data above "V"); OREX-1019 dose-dependently decreased the number of infusions obtained. According to a repeated-measures ANOVA, there was a significant effect of dose $(\mathrm{F}[4,18]=13.0, P<0.001)$, with 0.1 and $0.3 \mathrm{mg} / \mathrm{kg}$ OREX-1019 significantly decreasing the number of infusions obtained compared with vehicle.

\section{OREX-1019 Suppression of Responding Reinstated by Drug-Paired Stimuli Plus Noncontingent Infusion of Drug}

When monkeys responded for $0.00032 \mathrm{mg} / \mathrm{kg}$ per infusion of remifentanil, the mean number of responses on the active lever was $825 \pm 9$, which decreased to $4 \pm 3$ responses during extinction; when monkeys responded for $0.032 \mathrm{mg} / \mathrm{kg}$ per infusion of cocaine, the mean number of responses on the active lever was $765 \pm 58$, which decreased to $6 \pm 4$ responses during extinction (data not shown). Of 63 iterations through the procedure during this experiment, multiple extinction sessions were required on only two occasions. Presentation of drug-associated stimuli alone reinstated responding, with monkeys emitting $435 \pm 43$ responses following noncontingent administration of saline (i.e., drug-associated stimuli alone; data not shown). The number of responses increased to $735 \pm 45$ responses following noncontingent administration of $0.032 \mathrm{mg} / \mathrm{kg}$ heroin in addition to drug-associated stimuli 
A

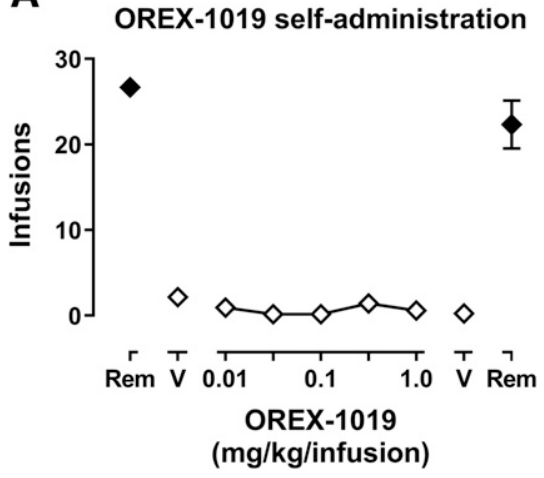

B OREX-1019 suppression of remifentanil self-administration

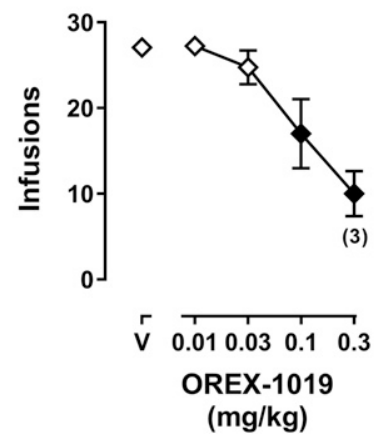

Fig. 1. (A) Evaluation of the reinforcing effects of OREX1019 using i.v. drug self-administration. The number of infusions obtained of $0.00032 \mathrm{mg} / \mathrm{kg}$ per infusion remifentanil, vehicle, and varying unit doses of OREX-1019 are plotted for monkeys $(n=4)$ responding under a FR 30: timeout 180-second schedule of reinforcement. Data points indicate the mean ( \pm 1 S.E.M.) of the number of infusions obtained during the last three sessions of each condition. Data above "Rem" and "V" indicate the number of infusions obtained during tests with remifentanil and vehicle, respectively, conducted at the beginning (left side) and end (right side) of the experiment. A one-factor, repeatedmeasures ANOVA was used to detect significant differences across condition; filled symbols indicate conditions that were significantly different from the first vehicle test $(P<$ 0.05). Ordinate: number of infusions in 90-minute selfadministration sessions. Abscissa: remifentanil (above "Rem"), vehicle (above "V"), or unit dose OREX-1019 in $\mathrm{mg} / \mathrm{kg}$. (B) Effects of OREX-1019 pretreatment on selfadministration of $0.00032 \mathrm{mg} / \mathrm{kg}$ per infusion remifentanil in monkeys $(n=4)$ responding under a FR 30:timeout 180second schedule of reinforcement. Data points indicate the mean ( \pm 1 S.E.M.) of the number of infusions obtained following pretreatment with vehicle (data above "V") and increasing doses of OREX-1019; only three monkeys were tested with the largest dose of OREX-1019 $(0.3 \mathrm{mg} / \mathrm{kg})$ indicated in the parentheses. A one-factor, repeatedmeasures ANOVA was used to detect significant differences across dose of OREX-1019; filled symbols indicate doses that were significantly different from vehicle $(P<0.05)$. Ordinate: number of infusions of remifentanil obtained in 90-minute self-administration sessions. Abscissa: dose of OREX-1019 in mg/kg.
(Fig. 2A, data above "V"). OREX-1019 dose-dependently decreased the number of responses emitted following noncontingent administration of heroin plus drug-associated stimuli $(\mathrm{F}[3,15]=11.7, P=0.002)$, with a dose of $0.1 \mathrm{mg} / \mathrm{kg}$ OREX1019 significantly attenuating responding reinstated by heroin. When combined with response-contingent presentation of drug-associated stimuli, noncontingent administration of $0.32 \mathrm{mg} / \mathrm{kg}$ cocaine reinstated responding, with monkeys emitting, on average, $487 \pm 116$ responses (Fig. 2B, data above "V"); OREX-1019 did not significantly alter responding that was reinstated by cocaine $(\mathrm{F}[3,15]=0.9, P=0.48)$.

\section{OREX-1019- and Naltrexone-Precipitated Withdrawal}

Food-Maintained Operant Behavior. In monkeys receiving twice-daily injections of morphine (see above), vehicle administration on day 1 of the naltrexone test did not systematically alter mean rate of food-maintained lever pressing across blocks within the session; response rate ranged from $0.51 \pm 0.18$ to $0.65 \pm 0.25$ responses per second across blocks (Fig. 3A, circles). Pretreatment with $0.1 \mathrm{mg} / \mathrm{kg}$ naltrexone on day 2 markedly decreased responding across all blocks (Fig. 3A, squares), with responding recovering the following day (Fig. 3A, triangles). According to a two-way, repeated-measures ANOVA, there was a significant main effect of day of treatment $(\mathrm{F}[2,59]=5.8, P=0.04)$ but no main effect of time of day $(P=0.52)$ and no day of treatment by time of day interaction $(P=0.19)$.

Following vehicle treatment on day 1 of the OREX-1019 test, mean response rates did not vary systematically across blocks, ranging from $0.40 \pm 0.25$ to $0.76 \pm 0.44$ responses per second (Fig. 3B, circles). Pretreatment with $0.3 \mathrm{mg} / \mathrm{kg}$

\section{A OREX-1019 suppression of} cue- and heroin-primed reinstatement

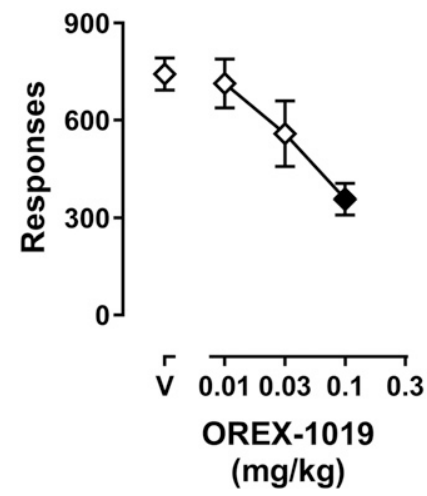

\section{B OREX-1019 suppression of cue- and cocaine-primed reinstatement}
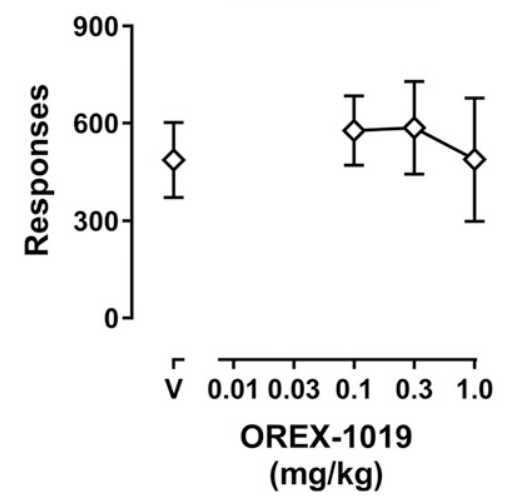

Fig. 2. Effects of OREX-1019 on responding previously maintained by (A) $0.00032 \mathrm{mg} / \mathrm{kg}$ per infusion remifentanil and reinstated by $0.032 \mathrm{mg} / \mathrm{kg}$ heroin in monkeys $(n=4)$ and (B) on responding that was previously maintained by $0.032 \mathrm{mg} / \mathrm{kg}$ per infusion cocaine and reinstated by $0.32 \mathrm{mg} / \mathrm{kg}$ cocaine in monkeys $(n=4)$. For both panels, data points indicate the mean ( \pm 1 S.E.M.) number of responses during reinstatement sessions in which they received a noncontingent injection of drug at the start of the session combined with response-contingent presentation of drug-associated stimuli. A one-factor, repeated-measures ANOVA was used to detect significant differences across dose of OREX-1019; filled symbols indicate doses that were significantly different from vehicle $(P<0.05)$. Ordinate: number of responses in 90-minute reinstatement sessions. Abscissa: dose of OREX-1019 in $\mathrm{mg} / \mathrm{kg}$. 
‥ Day 1: Vehicle

$\square \diamond$ Day 2: Test

$\neg$ Day 3: No injection

A

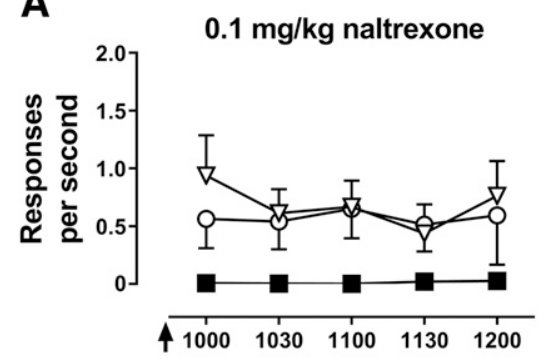

B

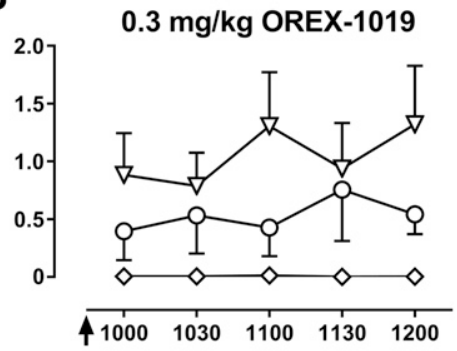

Time (hr) of day

Fig. 3. Effects of (A) naltrexone or (B) OREX-1019 on foodmaintained operant behavior in monkeys $(n=4)$ treated twice daily with morphine (see text for details about the dosing regimen). Response rate is plotted for each of five response periods across three test sessions. On day 1 (circles), vehicle was injected s.c. 15 minutes prior to the session (0945 hours, indicated by the arrow); on day 2, $0.1 \mathrm{mg} / \mathrm{kg}$ naltrexone [squares, (A)] or $0.3 \mathrm{mg} / \mathrm{kg}$ OREX1019 [diamonds, (B)] was injected s.c. prior to the session; and no injection was given on day 3 (triangles). Data points indicate the mean ( \pm 1 S.E.M.). A two-factor, repeatedmeasures ANOVA was used to detect significant differences across days of treatment and time of day; filled symbols indicate time points on day 2 (immediately following the test injection) that differ significantly from the vehicle injection given on day $1(P<0.05)$. Ordinate: responses per second during the response period. Abscissa: time of each response period.
OREX-1019 on day 2 markedly decreased responding across all blocks (Fig. 3B, diamonds), with responding recovering the following day (Fig. 3B, triangles). According to a two-way, repeated-measures ANOVA, there was no significant main effect of day of treatment $(P=0.06)$ or time of day $(P=0.31)$, and there was no day of treatment by time of day interaction $(P=0.08)$.

Blood Pressure. During the hour preceding the test injection, mean blood pressure ranged from $83.0 \pm 5.3$ to $85.7 \pm 3.9 \mathrm{mmHg}$ across days (Fig. $4, \mathrm{~A}$ and $\mathrm{B}$, data above 845 hours). Injection of vehicle on day 1 of the test (circles) did not impact blood pressure; however, injection of $0.1 \mathrm{mg} / \mathrm{kg}$ naltrexone the following day (day 2, squares) significantly increased blood pressure to $123 \pm 4 \mathrm{mmHg}$ during the hour immediately following the injection, with blood pressure remaining elevated for up to 4 hours, compared with the corresponding time points following vehicle injection on the previous day (filled symbols). Blood pressure during the same time period on day 3 (triangles) was not different from vehicle (day 1). According to a two-way, repeated-measures ANOVA, there were significant main effects of day of treatment $(\mathrm{F}[2,59]$ $=23.8, P=0.001)$ and time of day $(\mathrm{F}[4,59]=18.2, P<0.001)$ as well as a significant time of day-by-day interaction $(\mathrm{F}[8,59]$ $=15.0, P<0.001)$.

Injection of OREX-1019 (Fig. 4B, diamonds) increased blood pressure to $120.9 \pm 3.9 \mathrm{mmHg}$ during the hour following injection, with blood pressure remaining elevated for up to 4 hours. Compared with day 1 , blood pressure was significantly increased at the 845- and 1145-hour time points on the following day (day 3) when no test injection was given. According to a two-way, repeated-measures ANOVA, there were significant main effects of day of treatment $(\mathrm{F}[2,59]$ $=7.0, P=0.03)$ and time of day $(\mathrm{F}[4,59]=16.51, P<0.001)$ as well as a significant day of treatment by time-of-day interaction $(\mathrm{F}[8,59]=14.0, P<0.001)$.

Heart Rate. During the hour preceding the daily test injection, mean heart rate ranged from $87.8 \pm 8.3$ to $104.0 \pm$ 7.5 beats per minute across days (Fig. 4, C and D, data above 845 hours). Injection of vehicle on day 1 of the naltrexone test (circles) did not alter heart rate. However, injection of $0.1 \mathrm{mg} / \mathrm{kg}$ naltrexone on day 2 (squares) significantly increased heart rate to $188.4 \pm 7.1$ beats per minute for the hour immediately following the injection, with heart rate remaining elevated for up to 4 hours following the injection. Heart rate was significantly increased during the first time point on day 3 , relative to day 1 , but was not different during other time points. According to a two-way, repeated-measures ANOVA, there were significant main effects of day of treatment $(\mathrm{F}[2,59]=144.2, P<0.001)$ and time of day $(\mathrm{F}[4,59]=$ $29.1, P<0.001)$ and as well as a significant day of treatment by time-of-day interaction $(\mathrm{F}[8,59]=43.7, P<0.001)$.

Injection of OREX-1019 increased heart rate to $186.8 \pm 7.0$ beats per minute during the hour following injection, with heart rate remaining elevated for up to 4 hours following injection. Heart rate was significantly lower at 0945 hours and higher at 1145 hours on day 3 compared with day 1 , although, in both cases, the differences were very modest. According to a two-way, repeated-measures ANOVA, there were significant main effects of day of treatment $(\mathrm{F}[2,59]=44.6, P<0.001)$ and time of day $(\mathrm{F}[4,59]=45.8, P<0.001)$ as well as a significant day of treatment by time-of-day interaction $(\mathrm{F}[8,59]=30.5$, $P<0.001)$.

Body Temperature. During the hour preceding the daily test injection, mean body temperature ranged from $36.7 \pm 0.4$ to $36.9 \pm 0.9^{\circ} \mathrm{C}$ across days (Fig. $4, \mathrm{E}$ and $\mathrm{F}$, data above 845 hours). Injection of $0.1 \mathrm{mg} / \mathrm{kg}$ naltrexone significantly increased temperature to $37.4 \pm 0.4^{\circ} \mathrm{C}$ during the hour immediately following the injection (Fig. 4E, square over 945 hours); during subsequent time points, temperature did not differ from vehicle. According to a two-way, repeatedmeasures ANOVA, there was no main effect of day of treatment $(P=0.65)$, but there was a significant main effect of time of day $(\mathrm{F}[4,59]=20.9, P<0.001)$ as well as significant day of treatment and time-of-day interaction $(\mathrm{F}[8,59]=4.5$, $P=0.002$ ).

Injection of $0.3 \mathrm{mg} / \mathrm{kg}$ OREX-1019 significantly decreased body temperature 2 to 4 hours postinjection, as compared with vehicle, with the maximal decrease occurring 4 hours after the injection (Fig. 4F, diamonds). According to a two-way, repeatedmeasures ANOVA, there were significant main effects of day of treatment $(\mathrm{F}[2,59]=7.6, P=0.02)$ and time of day $(\mathrm{F}[4,59]$ $=5.4, P=0.01$ ) as well as a significant time-by-day interaction $(\mathrm{F}[8,59]=5.3, P<0.001)$.

Activity. During the hour preceding the daily test injection, mean activity ranged from $386.1 \pm 58.5$ to $641.3 \pm 81.2$ counts across days (Fig. 4, G and H, data above 845 hours). Injection of naltrexone significantly increased activity, compared with vehicle, during the first and third hours following the injection (Fig. 4G, squares above 0945 and 1145 hours). According to a two-way, repeated-measures ANOVA, there 


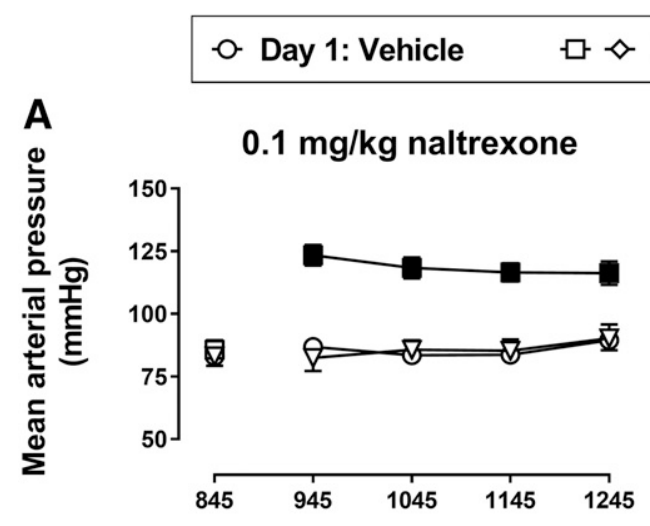

C

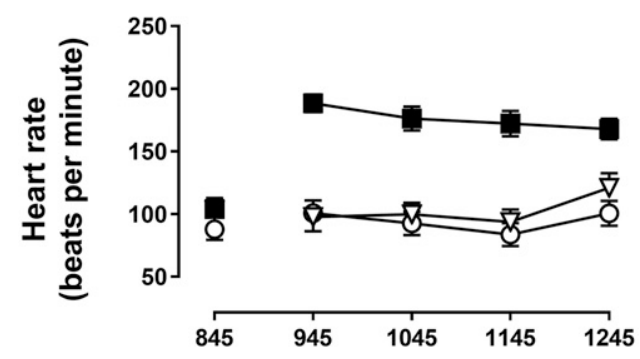

E

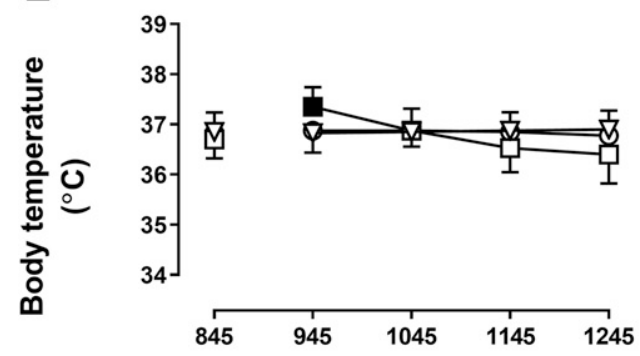

G
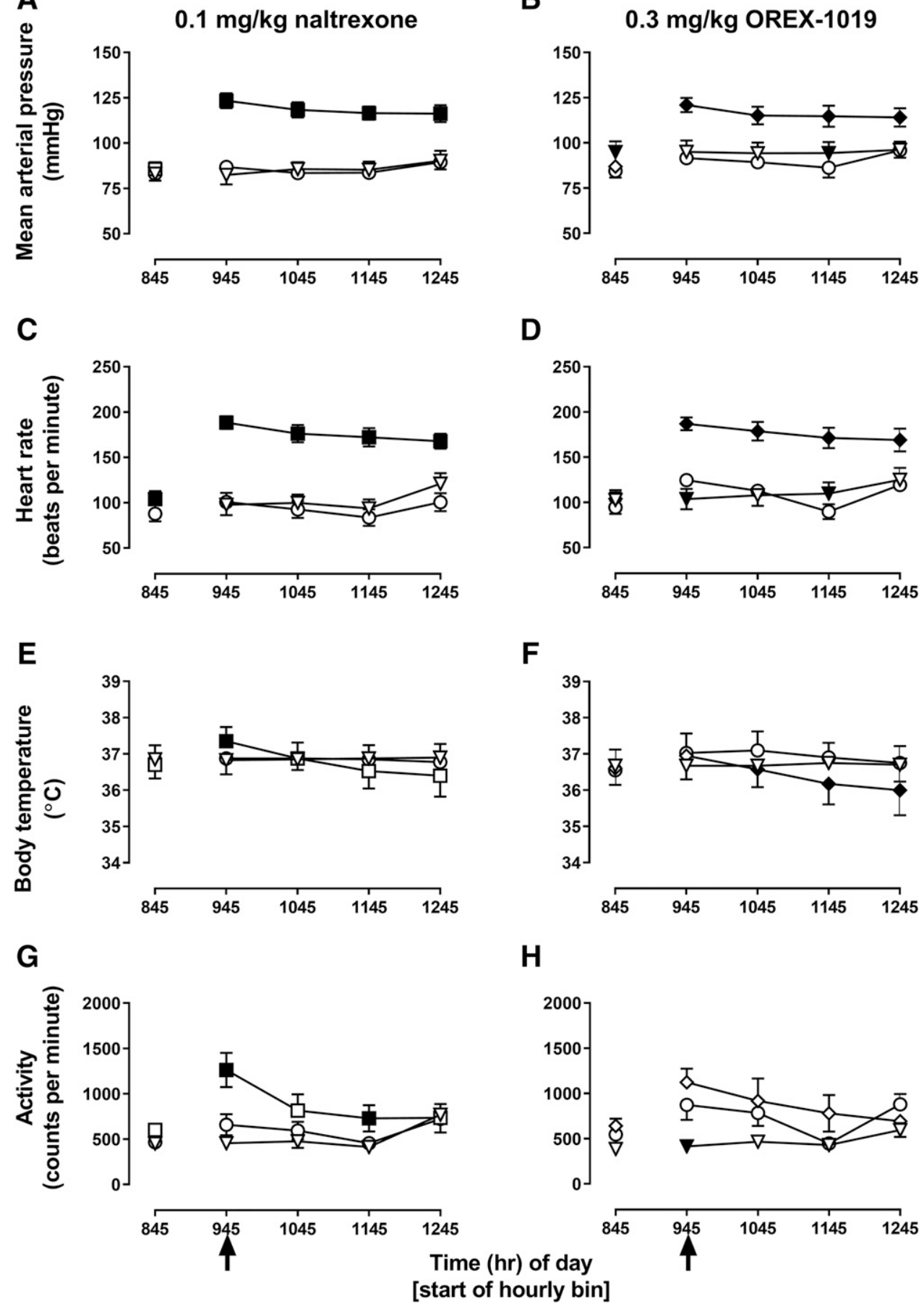

B

D

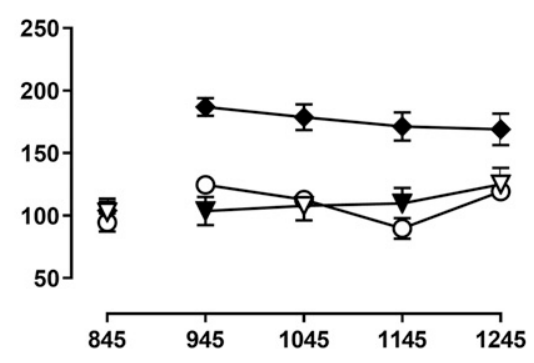

$\mathbf{F}$

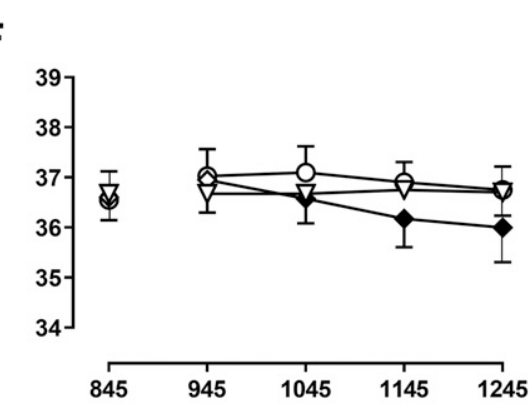

H

minute). Abscissa: time corresponding to
ming the beginning of each hourly bin.
Fig. 4. Effects of naltrexone or OREX1019 on blood pressure (A and B), heart rate $(\mathrm{C}$ and $\mathrm{D})$, body temperature $(\mathrm{E}$ and $\mathrm{F}$ ), and activity ( $\mathrm{G}$ and $\mathrm{H}$ ) in monkeys $(n=4)$ treated twice daily with morphine (see text for details about the dosing regimen). Data are plotted for the hour preceding (above 0845 hours) and for up to 4 hours following injection of vehicle (circles), $0.1 \mathrm{mg} / \mathrm{kg}$ naltrexone (squares, left column), or $0.3 \mathrm{mg} / \mathrm{kg}$ OREX-1019 (diamonds, right column). On day 1 (circles), vehicle was injected s.c. 15 minutes prior to the session (0945 hours, indicated by the arrow); on day 2, naltrexone (squares, left column) or OREX-1019 (diamonds, right column) was injected s.c. prior to the session; and on day 3 (triangles), no injection was given. Data points indicate the mean ( \pm 1 S.E.M.). A two-factor, repeated-measures ANOVA was used to detect significant differences across day of treatment and time of day; filled symbols indicate time points that differ significantly from the vehicle injection given on day $1(P<0.05)$. Ordinate: mean arterial pressure (millimeters of mercury); heart rate (beats per minute); body temperature (degree Celsius); activity (counts per were significant main effects of day of treatment $(\mathrm{F}[2,59]=$ $5.6, P=0.04)$ and time of day $(\mathrm{F}[4,59]=6.6, P=0.005)$ as well as a significant day of treatment by time-of-day interaction $(\mathrm{F}[8,59]=8.3, P<0.001)$.

Injection of OREX-1019 did not significantly alter activity, compared with vehicle (Fig. $4 \mathrm{H}$ ). On day 3 of the test (no injection), activity was significantly lower during the hour starting at 0945 hours compared with vehicle (triangle). According to a two-way, repeated-measures ANOVA, there was no main effect of day of treatment $(P=0.06)$, but there was a significant main effect of time of day $(\mathrm{F}[4,59]=13.0$, $P<0.001$ ) and a significant day of treatment by time of day $(\mathrm{F}[8,59]=2.8, P=0.03)$.

Behavioral Signs. On vehicle treatment days, the mean number of withdrawal signs ranged from $1.1 \pm 0.7$ to $2.3 \pm 0.8$ across observation periods (Fig. 5 , circles). Pretreatment with $0.1 \mathrm{mg} / \mathrm{kg}$ naltrexone nominally, but not significantly due to variance in the magnitude of effect across individuals, 
increased the number of signs, compared with vehicle, with a maximum of $4.9 \pm 1.8$ occurring 1 hour after treatment (Fig. 5A, square above 1045 hours). According to a two-way, repeated-measures ANOVA, there were no main effects of day of treatment $(P=0.44)$ or time of day $(P=0.47)$ and no day of treatment by time of day interaction $(P=0.60)$.

Injection of $0.3 \mathrm{mg} / \mathrm{kg}$ OREX-1019 significantly increased the number of signs to $7.3 \pm 1.0$ and $5.3 \pm 1.4$ at 1.0 and 1.5 hours after treatment, respectively (Fig. 5B, filled diamonds above 1045 and 1115 hours). According to a two-way, repeated measures ANOVA, there were significant main effects of day of treatment $(\mathrm{F}[1,39]=61.4, P=0.004)$ and time of day $(\mathrm{F}[4,39]=4.0, P=0.03)$ but no day of treatment by time of day interaction $(P=0.25)$.

Pharmacokinetic Properties. PK parameters evaluated in rats, cynomolgus monkeys, and rabbits are shown in Table 1 and Supplemental Fig. 1. In rats, there was poor oral bioavailability, but much higher after s.c. dosing (120\%). Interestingly, $\mathrm{T}_{\max }$ for the s.c. route was reached quickly, being equivalent to the $\mathrm{T}_{\max }$ after oral administration. In cynomolgus monkeys, bioavailability was low via the oral route, and slow absorption meant $\mathrm{T}_{\max }$ was at 8 hours, after which the elimination phase mimicked that seen after i.v. administration. In rabbits, the elimination phase was very similar for both i.v. and s.l. routes, whereas slow elimination was observed following s.c. administration; s.c. bioavailability was $58.3 \%$ and for s.l. it was $12.2 \%$, suggesting that both were feasible routes of administration.

Additional characterization of OREX-1019 distribution, metabolism, and safety was conducted to determine whether it was a good candidate for further clinical development; these data are shown in Supplemental Table 1. It displayed excellent chemical stability in plasma, blood, and other biologic fluids (gastric, intestinal); only displayed interactions with the CYP-3A isoform (typical of many opioids); and was not a substrate for P-glycoprotein. In a screen against 62 off-target radioligand and enzyme assays, OREX-1019 showed no off-target effects at $100 \mathrm{nM}(\sim 500$ times the Ki at opioid receptors) and only at 10,000 $\mathrm{nM}$ (i.e., 50,000 times the $\mathrm{Ki}$ ) could $50 \%$ inhibition be reached at CB1 and sodium site 2 proteins (Supplemental Table 2). In the hERG safety assay, an $\mathrm{IC}_{50}$ value could not be calculated for OREX-1019, only reaching $39 \%$ inhibition at $25 \mu \mathrm{M}$.

Additional Safety Characterization of OREX-1019. OREX-1019 did not significantly alter GI transit up to a dose of $100 \mathrm{mg} / \mathrm{kg}$, whereas $30 \mathrm{mg} / \mathrm{kg}$ morphine significantly decreased length of charcoal transit (Supplemental Fig. 2A). OREX-1019 did not significantly alter Rotorod performance, whereas $10 \mathrm{mg} / \mathrm{kg}$ diazepam significantly decreased time spent on the Rotorod (Supplemental Fig. 2B).

\section{Discussion}

There is a clear unmet medical need for more efficient and effective methods to treat relapse to drug use, particularly for opioids, cocaine, and alcohol. The very high rate of relapse to drug taking after a period of abstinence continues to be a major problem in the treatment of substance use disorders (Sinha et al., 2011). A variety of factors contributes to relapse, including re-exposure to the drug, exposure to stimuli associated with the previous drug use, and stress. In addition, the majority of drug abusers, both experienced and new drug users (including young people), use more than one substance, underscoring the need for medications that are effective with multiple drug classes (Pakula et al., 2009; Olthuis, et al., 2013). A combination of buprenorphine and naltrexone attenuates both drug- and stress-induced relapse to drugseeking behavior in rats (Cordery et al., 2014), whereas selective KOPr antagonists are reported to be effective only for stress-induced relapse (Bruchas et al., 2010). This supports the notion that a polypharmacological approach to relapse prevention may have broader clinical utility than could be obtained with selective agents. The current study determined the effectiveness of OREX-1019, a single compound that mimics the effects of a buprenorphine/naltrexone combination, to reduce ongoing drug taking as measured with selfadministration as well as to block relapse as measured with a drug- and cue-primed reinstatement procedure.

In the current study, pretreatment with OREX-1019 dosedependently decreased responding for the MOPr agonist remifentanil in rhesus monkeys, with doses of 0.1 and $0.3 \mathrm{mg} / \mathrm{kg}$ producing significant effects. In the same group of monkeys, OREX-1019 did not maintain levels of responding above vehicle when it was available for self-administration, suggesting that OREX-1019 itself has low abuse potential. In the self-administration experiment, OREX-1019 was studied across a 2-log unit range of doses and up to a unit dose (1.0 $\mathrm{mg} / \mathrm{kg}$ per infusion) that was 10 -fold larger than a dose that attenuated responding for remifentanil. The ability of OREX-1019 to reduce responding for a MOPr agonist is consistent with the activity of MOPr antagonists such as naltrexone or the long-acting pseudo-irreversible antagonist

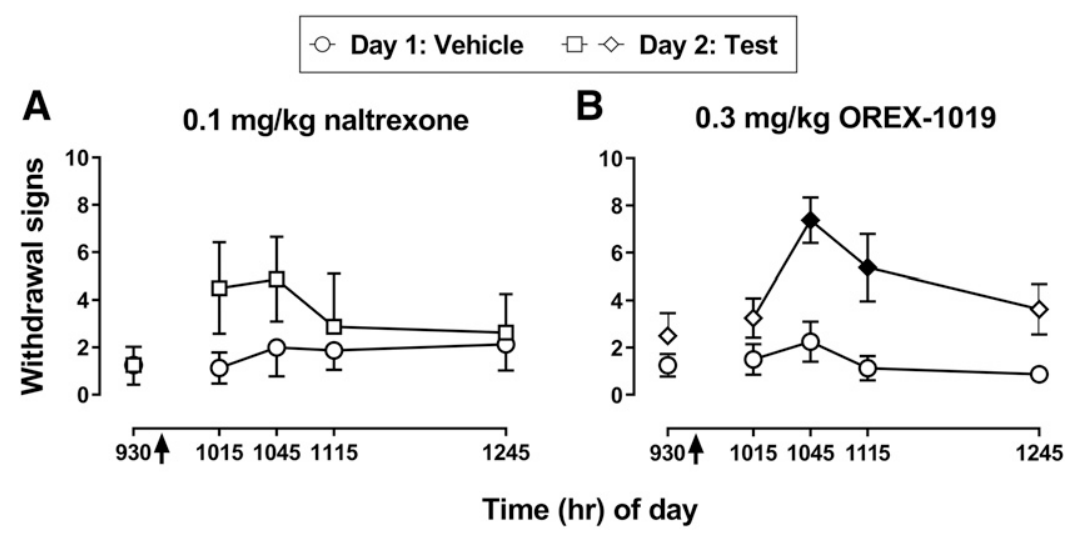

Fig. 5. Effects of (A) naltrexone or (B) OREX-1019 on directly observable withdrawal signs in monkeys $(n=4)$ treated twice daily with morphine (see text for details about the dosing regimen). The total number of signs observed is plotted for each of five time points beginning with 15 minutes prior ( 0930 hours) to the daily test injection. On day 1 (circles), vehicle was injected s.c. 15 minutes prior to the session (0945 hours, indicated by the arrow); on day $2,0.1 \mathrm{mg} / \mathrm{kg}$ naltrexone [squares, (A)] or $0.3 \mathrm{mg} / \mathrm{kg}$ OREX1019 [diamonds, (B)] was injected s.c. prior to the session. Data points indicate the mean ( \pm 1 S.E.M.). A two-factor, repeated-measures ANOVA was used to detect significant differences across day of treatment and time of day; filled symbols indicate times that differ significantly from the vehicle injection given on day $1(P<0.05)$. Ordinate: responses per second during each response period. Abscissa: time of each observation period. 
TABLE 1

Pharmacokinetic parameters of OREX-1019

\begin{tabular}{|c|c|c|c|c|c|c|c|c|}
\hline & \multicolumn{3}{|l|}{ Rat } & \multicolumn{2}{|c|}{ Nonhuman Primate } & \multicolumn{3}{|l|}{ Rabbit } \\
\hline & i.v. $1 \mathrm{mg} / \mathrm{kg}$ & p.o. $3 \mathrm{mg} / \mathrm{kg}$ & s.c. $3 \mathrm{mg} / \mathrm{kg}$ & i.v. $3 \mathrm{mg} / \mathrm{kg}$ & p.o. $30 \mathrm{mg} / \mathrm{kg}$ & i.v. $3.6 \mathrm{mg} / \mathrm{kg}$ & s.c. $10 \mathrm{mg} / \mathrm{kg}$ & s.l. $30 \mathrm{mg} /$ Rabbit $^{a}$ \\
\hline $\mathrm{C}_{\max }(\mathrm{ng} / \mathrm{ml})$ & 463 & 3.72 & 584 & 1290 & 31.3 & 1161 & 161 & 78.0 \\
\hline $\mathrm{T}_{\max }(\mathrm{hr})$ & 0 & 0.333 & 0.333 & 0 & 8 & 0 & 4.4 & 1.0 \\
\hline $\mathrm{t}_{1 / 2}(\mathrm{hr})$ & 2.07 & ND & 3.22 & 4.14 & 7.11 & 4.01 & ND & 4.13 \\
\hline $\mathrm{MRT}_{\text {last }}(\mathrm{hr})$ & 1.38 & 1.44 & 2.50 & 2.85 & 7.89 & 3.10 & 8.83 & 4.44 \\
\hline CL (1/hr per kilogram) & 2.90 & NA & NA & 1.03 & NA & 2.69 & NA & NA \\
\hline $\mathrm{V}_{\mathrm{ss}}(\mathrm{l} / \mathrm{kg})$ & 4.30 & NA & NA & 6.42 & NA & 9.65 & NA & NA \\
\hline $\mathrm{AUC}_{\text {last }}(\mathrm{hr} \times \mathrm{ng} / \mathrm{ml})$ & 350 & 5.88 & 1269 & 2971 & 442 & 1294 & 2114 & 418 \\
\hline $\mathrm{AUC}_{\infty}(\mathrm{hr} \times \mathrm{ng} / \mathrm{ml})$ & 355 & ND & 1275 & 2998 & 471 & 1348 & ND & 426 \\
\hline DAUC $_{\text {last }} b(\mathrm{hr} \times \mathrm{kg} \times \mathrm{ng} / \mathrm{ml} / \mathrm{mg})$ & 350 & 1.96 & 423 & 990 & 14.7 & 362 & 211 & 45.3 \\
\hline $\mathrm{DAUC}_{\infty}{ }^{b}(\mathrm{hr} \times \mathrm{kg} \times \mathrm{ng} / \mathrm{ml} / \mathrm{mg})$ & 355 & ND & 425 & 999 & 15.7 & 378 & $\mathrm{ND}^{c}$ & 46.2 \\
\hline Bioavailability $^{d}(\%)$ & NA & ND & 120 & NA & 1.49 & NA & 58.3 & 12.2 \\
\hline
\end{tabular}

$\mathrm{AUC}_{\text {last }}$, area under the curve, calculated to the last observable time point; AUC $\infty$, area under the curve, extrapolated to infinity; DAUC, dose-normalized $\mathrm{AUC}$; MRT last mean residence time, calculated to the last observable time point; ND, not determined; $t_{1 / 2}$, half-life; CL, clearance; Vss, apparent volume of distribution at steady state

${ }^{a}$ Thirty milligrams per rabbit $(9.17 \mathrm{mg} / \mathrm{kg}$ average).

${ }^{b}$ Dose-normalized by dividing the parameter by the nominal dose in milligrams per kilogram.

${ }^{c}$ Not determined because the terminal elimination phase was not observed.

${ }^{d}$ Bioavailability determined by dividing the individual p.o., s.c., or s.l. $\mathrm{DAUC}_{\text {last }}$ values by the average i.v. $\mathrm{DAUC}$ last $\mathrm{value}$

methocinnamox under similar conditions (e.g., Maguire et al., 2019) and confirms the previous in vitro studies showing that OREX-1019 has substantially lower efficacy than buprenorphine at MOPr as measured with a $\left[{ }^{35} \mathrm{~S}\right] \mathrm{GTP} \gamma \mathrm{S}$-binding assay (Cueva et al., 2015). MOPr antagonist effects of OREX-1019 were also demonstrated in the precipitated-withdrawal experiments, wherein OREX-1019, like naltrexone, elicited signs of withdrawal when administered to monkeys treated chronically with morphine (although behavioral observations did not reach statistical significance for naltrexone). Both OREX-1019 and naltrexone significantly increased heart rate and blood pressure, produced overt observable signs, and eliminated food-maintained responding. These effects are hallmarks of opioid receptor antagonist-precipitated withdrawal in nonhuman primates treated chronically with a MOPr agonist (e.g., Becker et al., 2008). For both naltrexone and OREX-1019, increases in blood pressure and heart rate and suppression of food-maintained responding were sustained for at least 4 hours following injection of the test drug, but all measures returned to baseline levels the following day and after monkeys continued to receive daily morphine treatments.

OREX-1019 significantly decreased cue- and heroin-primed reinstatement of extinguished responding in monkeys that self-administered remifentanil, with a dose of $0.1 \mathrm{mg} / \mathrm{kg}$ producing a significant effect. In contrast, doses of OREX-1019 up to $1.0 \mathrm{mg} / \mathrm{kg}$ did not alter cue- and cocaine-primed reinstatement of responding in monkeys that previously selfadministered cocaine. Selective decreases in heroin- but not cocaine-primed reinstatement are also consistent with OREX1019 having very low efficacy at MOPr. The dose of OREX1019 that decreased responding reinstated by heroin also decreased self-administration of remifentanil. These data are in contrast with the results from rodent studies (Cordery et al., 2014) using a buprenorphine/naltrexone combination, although others (e.g., Comer et al., 1993) have suggested that MOPr agonist properties are important for the ability of buprenorphine to block cocaine-primed reinstatement of responding.

Given the structural similarity to buprenorphine, it was expected that OREX-1019 would display qualitatively similar pharmacokinetic characteristics. This has proven to be the case with low oral bioavailability in both rats and nonhuman primates that can be attributed to a substantial first pass effect, indicated by the rapid metabolism in liver preparations. To avoid presystemic metabolism, buprenorphine is successfully delivered in humans by the sublingual and transdermal routes, and the current data confirming good bioavailability after s.c. and s.l. administration would suggest a similar approach could be taken with OREX-1019. OREX-1019 has demonstrated excellent selectivity for the target receptors with little-to-no interactions with off-target proteins, including the hERG channel.

In conclusion, important advances have been made by various research groups, including our own, that confirm a polypharmacological approach is most likely to lead to relapse prevention therapies with broadest therapeutic utility. With this in mind, we have developed OREX-1019 and confirmed in nonhuman primates that it is effective in assays predictive of utility in the treatment of opioid use disorder.

\section{Acknowledgments}

Data reported in Supplemental Table 2 provided by National Institute on Drug Abuse (Addiction Treatment Discovery Program, Division of Pharmacotherapies and Medical Consequences of Drug Abuse).

\section{Authorship Contributions}

Participated in research design: Maguire, Gerak, France, Belli, Flynn.

Conducted experiments: Maguire, Gerak.

Contributed new reagents or analytic tools: Husbands, CamiKobeci.

Performed data analysis: Maguire, Gerak, Belli.

Wrote or contributed to the writing of the manuscript: Maguire, Gerak, Cami-Kobeci, Husbands, France, Belli, Flynn.

\section{References}

Almatroudi A, Ostovar M, Bailey CP, Husbands SM, and Bailey SJ (2018) Antidepressant-like effects of BU10119, a novel buprenorphine analogue with mixed $\kappa / \mu$ receptor antagonist properties, in mice. Br J Pharmacol 175:2869-2880.

Bailey CP and Husbands SM (2014) Novel approaches for the treatment of psychostimulant and opioid abuse - focus on opioid receptor-based therapies. Expert Opin Drug Discov 9:1333-1344. 
Becker GL, Gerak LR, Koek W, and France CP (2008) Antagonist-precipitated and discontinuation-induced withdrawal in morphine-dependent rhesus monkeys. Psychopharmacology (Berl) 201:373-382.

Bruchas MR, Land BB, and Chavkin C (2010) The dynorphin/kappa opioid system as a modulator of stress-induced and pro-addictive behaviors. Brain Res 1314:44-55.

Chavkin C (2018) Kappa-opioid antagonists as stress resilience medications for the treatment of alcohol use disorders. Neuropsychopharmacology 43:1803-1804.

Comer SD, Lac ST, Curtis LK, and Carroll ME (1993) Effects of buprenorphine and naltrexone on reinstatement of cocaine-reinforced responding in rats. J Pharmacol Exp Ther 267:1470-1477.

Cordery SF, Taverner A, Ridzwan IE, Guy RH, Delgado-Charro MB, Husbands SM, and Bailey CP (2014) A non-rewarding, non-aversive buprenorphine/naltrexone combination attenuates drug-primed reinstatement to cocaine and morphine in rats in a conditioned place preference paradigm. Addict Biol 19:575-586.

Cueva JP, Roche C, Ostovar M, Kumar V, Clark MJ, Hillhouse TM, Lewis JW, Traynor JR, and Husbands SM (2015) C7 $\beta$-methyl analogues of the orvinols: the discovery of kappa opioid antagonists with nociceptin/orphanin FQ peptide (NOP) receptor partial agonism and low, or zero, efficacy at mu opioid receptors. J Med Chem 58:4242-4249.

Falcon E, Browne CA, Leon RM, Fleites VC, Sweeney R, Kirby LG, and Lucki I (2016) Antidepressant-like effects of buprenorphine are mediated by kappa opioid receptors. Neuropsychopharmacology 41:2344-2351.

Forray A and Sofuoglu M (2014) Future pharmacological treatments for substance use disorders. $\mathrm{Br} \mathrm{J}$ Clin Pharmacol 77:382-400.

Gerak LR and France CP (2016) Combined treatment with morphine and $\Delta 9$ tetrahydrocannabinol in rhesus monkeys: antinociceptive tolerance and withdrawal. J Pharmacol Exp Ther 357:357-366.

Gerak LR, Galici R, and France CP (2009) Self administration of heroin and cocaine in morphine-dependent and morphine-withdrawn rhesus monkeys. Psychopharmacology (Berl) 204:403-411.

Gerak LR, Zanettini C, Koek W, and France CP (2015) Cross-tolerance to cannabinoids in morphine-tolerant rhesus monkeys. Psychopharmacology (Berl) 232 $3637-3647$.

Gerak LR, Collins GT, and France CP (2016) Effects of Lorcaserin on Cocaine and Methamphetamine Self-Administration and Reinstatement of Responding Previously Maintained by Cocaine in Rhesus Monkeys. J Pharmacol Exp Ther 359 (3): 383-391, doi: 10.1124/jpet.116.236307 27650954.

Gerak LR, Collins GT, Maguire DR, and France CP (2019) Effects of lorcaserin on reinstatement of responding previously maintained by cocaine or remifentanil in rhesus monkeys. Exp Clin Psychopharmacol 27 (1):78-86, doi: 10.1037/pha0000234 30382731.

Gerra G, Fantoma A, and Zaimovic A (2006) Naltrexone and buprenorphine combination in the treatment of opioid dependence. $J$ Psychopharmacol 20:806-814.
Hersh D, Van Kirk JR, and Kranzler HR (1998) Naltrexone treatment of comorbid alcohol and cocaine use disorders. Psychopharmacology (Berl) 139:44-52.

Husbands SM (2013) Buprenorphine and related orvinols. Research \& Development of Opioid-Related Analgesics vol 1131:127-144, American Chemical Society, Washington, DC.

Johanson CE, Arfken CL, di Menza S, and Schuster CR (2012) Diversion and abuse of buprenorphine: findings from national surveys of treatment patients and physicians. Drug Alcohol Depend 120:190-195.

Maguire DR, Gerak LR, Woods JH, Husbands SM, Disney A, and France CP (2019) Long-lasting effects of methocinnamox on opioid self-administration in rhesus monkeys. J Pharmacol Exp Ther 368:88-99.

McCann DJ (2008) Potential of buprenorphine/naltrexone in treating polydrug addiction and co-occurring psychiatric disorders. Clin Pharmacol Ther 83:627-630.

Olthuis JV, Darredeau C, and Barrett SP (2013) Substance use initiation: the role of simultaneous polysubstance use. Drug Alcohol Rev 32:67-71.

Pakula B, Macdonald S, and Stockwell T (2009) Settings and functions related to simultaneous use of alcohol with marijuana or cocaine among clients in treatment for substance abuse. Subst Use Misuse 44:212-226.

Peckham AM, De La Cruz A, and Dufresne RL (2018) Kappa opioid receptor antagonism: are opioids the answer for treatment resistant depression? Ment Health Clin 8:175-183.

Robinson SA, Erickson RL, Browne CA, and Lucki I (2017) A role for the mu opioid receptor in the antidepressant effects of buprenorphine. Behav Brain Res 319:96-103.

Rösner S, Hackl-Herrwerth A, Leucht S, Vecchi S, Srisurapanont M, and Soyka M (2010) Opioid antagonists for alcohol dependence. Cochrane Database Syst Rev (12):CD001867.

Rothman RB, Gorelick DA, Heishman SJ, Eichmiller PR, Hill BH, Norbeck J, and Liberto JG (2000) An open-label study of a functional opioid kappa antagonist in the treatment of opioid dependence. J Subst Abuse Treat 18:277-281.

Sinha R, Shaham Y, and Heilig M (2011) Translational and reverse translationa research on the role of stress in drug craving and relapse. Psychopharmacology (Berl) 218:69-82.

Taverner A, Cordery S, Husbands SM, Guy RH, Delgado-Charro BM, and Bailey CP (2011) Transdermal delivery of a buprenorphine/naltrexone combination for the treatment of polydrug abuse. Pharmacol Rep 63:257.

Van't Veer A and Carlezon WA Jr (2013) Role of kappa-opioid receptors in stress and anxiety-related behavior. Psychopharmacology (Berl) 229:435-452.

Address correspondence to: Dr. Stephen M. Husbands, Department of Pharmacy and Pharmacology, University of Bath, Claverton Down, Bath, BA2 7AY, United Kingdom. E-mail: s.m.husbands@bath.ac.uk 